\title{
INTEGRATION OF SURVEYING TECHNIQUES TO DETECT THE IDEAL SHAPE OF A DOME: THE CASE OF THE ESCUELAS PÍAS CHURCH IN VALENCIA
}

\author{
Serena Artese ${ }^{1,{ }^{*}}$, José Luis Lerma ${ }^{2}$, Juan Aznar Molla ${ }^{3}$, Rafael Marín Sánchez ${ }^{3}$, Raffaele Zinno ${ }^{4}$ \\ ${ }^{1}$ Department of Civil Engineering, University of Calabria, Cubo 45/B, Via Pietro Bucci, 87036 Rende (CS), Italy, \\ serena.artese@unical.it \\ ${ }^{2}$ Photogrammetry \& Laser Scanner Research Group (GIFLE), Department of Cartographic Engineering, Geodesy and \\ Photogrammetry, Universitat Politècnica de València, $C^{o}$ de Vera, s/n, Building 7i, 46022 Valencia, Spain, jllerma@cgf.upv.es \\ ${ }^{3}$ Department of Architectural Constructions, Universitat Politècnica de València, $\mathrm{C}^{\mathrm{o}}$ de Vera, s/n, Building 1b, 46022 Valencia, \\ Spain, (jaznarm, rmarins)@upv.es \\ ${ }^{4}$ Department of Informatics, Modeling, Electronic and System Engineering, University of Calabria, Via P. Bucci cubo 42C, 87036 \\ Rende, Italy, raffaele.zinno@unical.it
}

Commission II

KEY WORDS: Laser scanner, Cultural heritage, Thermal camera, 3D modelling

\begin{abstract}
:
The three-dimensional (3D) documentation and surveying of cultural heritage can be carried out following several geomatics techniques such as laser scanning and thermography in order to detect the original 3D shape after applying reverse engineering solutions. In almost all cases, the integration of data collected by different instruments is needed to achieve a successful and comprehensive 3D model of the as-built architectural shape of the historical building. This paper describes the operations carried out by the authors to determine the as-built 3D model of the Escuelas Pias Church, related namely to the dome and circular nave. After the description of the church and historical notes, attention will be driven to the indirect registration results obtained with three different laser scanning software packages, highlighting similarities and differences, and the consequences while generating meshes. The 3D model carried out will then be described and the results of some investigations with regard to the hypotheses about the design of the dome and the origin of the alterations will be presented.
\end{abstract}

\section{INTRODUCTION}

State-of-the-art technological geomatics solutions and a wide range of sensors available today offer seamless interesting opportunities for both surveying and structural health monitoring (SHM) of buildings (Zinno et al., 2019), infrastructures, land and cultural heritage (Artese et al., 2018, 2015, 2013).

In the cultural heritage sector, the usage of geomatics techniques is related to both the acquisition phase (from which the given metric data are obtained), and the 3D plotting/modelling of complex objects, either of archaeological, artistic or architectural interest.

The preservation of cultural heritage requires a rigorous documentation both in historical and in artistic terms regarding the physical characteristics, shape, colour and geometry.

The acquisition and processing of data should be made following appropriate methods. The most commonly used methodologies are based primarily on image data (Portalés et al., 2009), multispectral data (Lerma, 2005) and range data (Artese, 2014). Total stations and GNSS receivers are still used for georeferencing and control point measurements. The different direct and indirect methodologies are increasingly integrated to take advantage of each technique (El-Hakim, 2004; Remondino et al., 2009). For image data, featureless approaches are currently used (Hammoudi et al., 2011), while for range data, the iterative closest point (ICP) method (Besl et al., 1992; Zhang, 1994; Gressin, 2013) is still mostly used. The goal and objectives of the survey, the influence of network geometry, the topography of the object, monument or site, and the materials' reflectivity should be taken into consideration before undertaking the laser scanning survey (Lerma et al., 2008).

This paper describes part of the comprehensive 3D survey of Escuelas Pías Church using terrestrial laser scanning for the geometric analysis and thermography for the thermal analysis. In addition, a digital camera was used for draping the imagery onto the 3D model. Two laser scanners were used to obtain the shape of the church, while for investigating the health status of the dome and to detect hidden cracks, a thermal camera was used. Some remarks will be made, regarding the hypotheses about the design of the dome.

\section{THE ESCUELAS PIAS CHURCH}

The "Escuelas Pías" (Figure 1) is a clerical religious order founded in the 17th century by St. José de Calasanz (15571648), dedicated to the apostolate and to the education of children and young people, especially the poor. It is the first free public school in Europe. To this order belongs the parish Church of St. Joaquin, also known as Escuelas Pías Church, located in the heart of the old town of Valencia (Spain). Characterized by a central and decagonal plan, the Church was built between 1767 and 1772 under the patronage of the Archbishop of Valencia Andrés Mayoral Alonso de Mella (1738-1769). The project supervisor was the architect Antonio Gilabert (1716-1792). Joseph Puchol started to design the first level between 1767 and 1768 .

\footnotetext{
* Corresponding author
} 


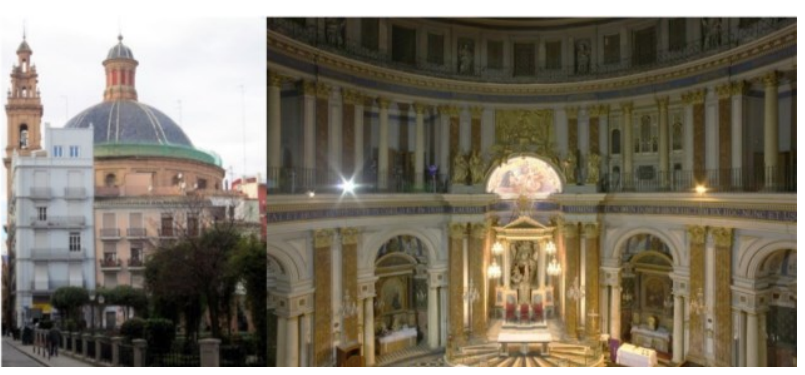

Figure 1. Iglesia de las Escuelas Pías (Valencia, Calle Carniceros, 2)

Antonio Gilabert modified the original plans of Puchol, and the ornament turned from Gothic to Baroque style with neoclassical insertions.

This church, with its imposing height of $48 \mathrm{~m}$, is dominated by a large hemispherical dome of about $24 \mathrm{~m}$ in diameter, surmounted by a lantern with a fairing. The dome rests on ten large trapezoid section pillars and ten subsidiary spaces occupied by several radial chapels (Figure 2).
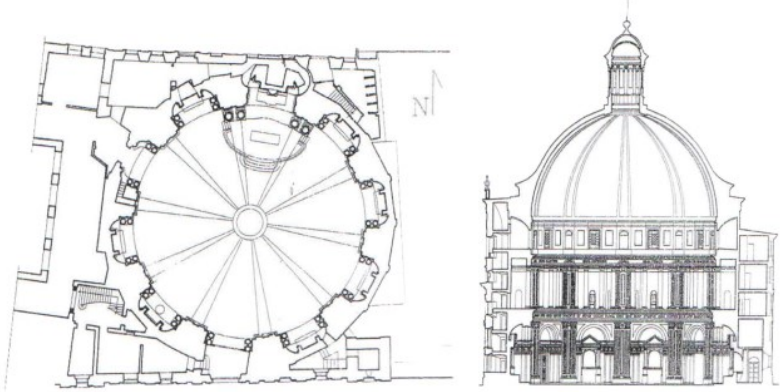

Figure 2. Plan and elevation of the Escuelas Pías Church (Verdú, 1996)

This temple can be seen as a representative example of the academic architecture of the late 18th century, due to the composition of the facade, the building itself and the architects involved in its construction. The Escuelas Pías Church represents a superb example where it is possible to appreciate the Classical turning point dictated by the creation in 1768 of the Real Academia de Bellas Artes de San Carlos, which through its architecture, encouraged the flowering of the Classical Baroque style prevalent from the mid-18th century in the city of Valencia.

\section{SURVEYING OPERATIONS}

The surveying operations were carried out with two terrestrial laser scanners, one reflex camera and a thermal camera (Figure $3)$. For the indoor survey of the Escuelas Pías Church, the FARO Focus3D S 120, one of the smallest and lightweight 3D laser scanners, was used.

To measure accurately the whole church inside and outside, 40 scans were acquired, with a $0.07 \%$ point resolution at a rate of 120,000 points/s. Figure 4 shows a panoramic view of one of the laser scanner acquisitions on the main altar.

Spherical targets with a diameter of $14 \mathrm{~cm}$ were distributed across the church and at various heights in order to facilitate the alignment/registration of scans in post-processing. The union of the registered point clouds is shown in Figure 5, either from inside and outside, summing up more than XX million points.
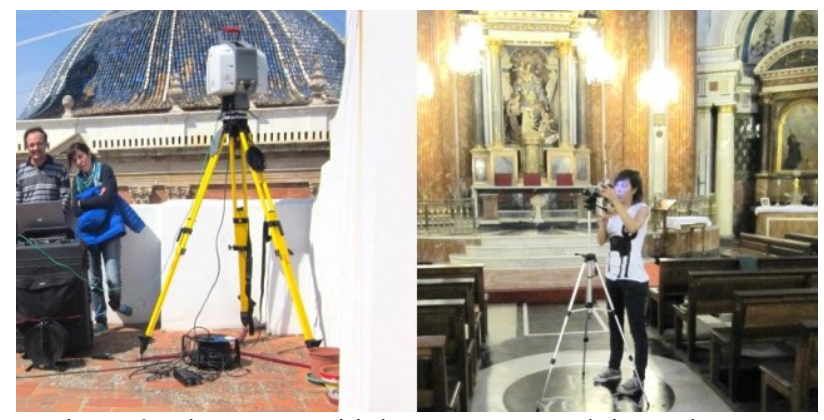

Figure 3. The survey with laser scanner and thermal camera

Global coordinates were not requested for this survey; therefore, no geodetic surveying was performed. In addition to the laser scanner acquisitions, 90 photos were taken in order to texture the 3D model.

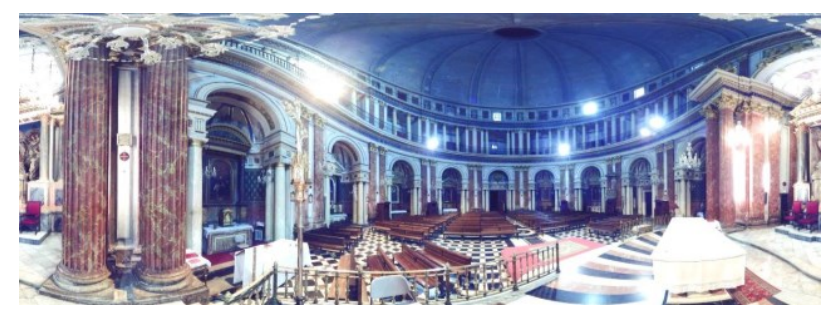

Figure 4. A panoramic view of laser scanner acquisitions

The external survey was carried out using a Leica Scan Station. A survey with a thermal camera was also carried out. The IR shots were used to detect hidden cracks, above all in the dome.
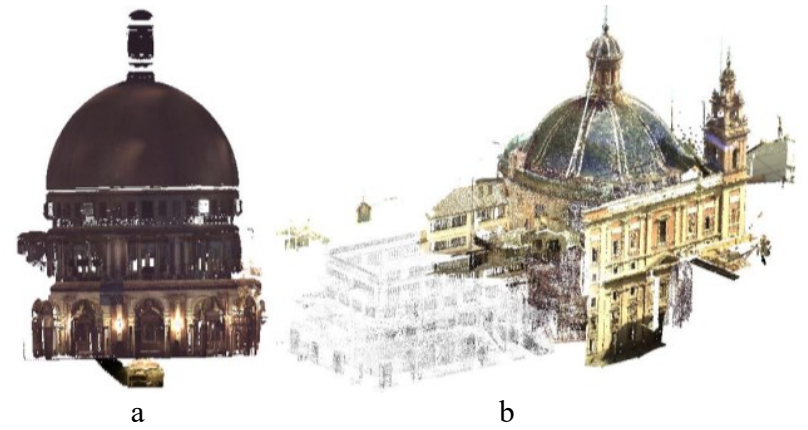

Figure 5. Aligned scans: a) view from inside; b) view from outside

\section{THE RESULTS}

\subsection{The Registration: comparison among different software}

With regard to the registration phase, the scans acquired were used to set up a comparison among different software (Artese et al., 2014). Four of the acquired laser scanning datasets were registered with three different software: Leica Cyclone, FARO Scene and 3DVEM - Register.

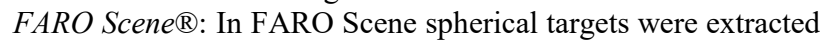
manually by selecting the points corresponding to each target scan and performing an optimization, due to the fact that the automatic spherical extraction did not work. In this way, the coordinates of the targets in different scans were determined. A group of aligned scans with a standard deviation of $2 \mathrm{~mm}$ was achieved.

Leica Cyclone ${ }^{\circledR}$ : Leica Cyclone Register is based on the transformation of a rigid body, in which the estimation of parameters is performed by least squares, following a closed 
form. A standard deviation of $2.2 \mathrm{~mm}$ was achieved for the aligned scans.

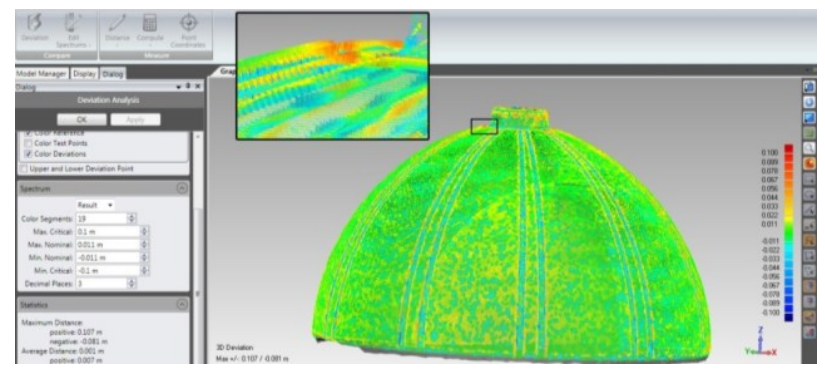

Figure 6. Comparison between model and point cloud

3DVEM - Register ${ }^{\circledR}$ : 3DVEM - Register is a low-cost and user-friendly software developed for registration of point clouds and/or 3D model datasets by GIFLE at the Universitat Politècnica de València. The registration can be solved either by least-squares adjustment or by robust estimators (both Danish Method and Minimum Sum) (Fabado et al., 2013). A standard deviation of $2.3 \mathrm{~mm}$ was obtained for the aligned scans.

To evaluate the registration performance, meshes were obtained from the registered point clouds. 3DReshaper ${ }^{\circledR}$ software was used for meshing. The comparison between the model and the point cloud, for all three clouds aligned with the three different software packages, was made in Geomagic Studio ${ }^{\circledR}$ software (Figure 6).

The regular intrados dome of the church was used as a testing area. The different points-deviations model results are presented in Table 1.

\begin{tabular}{|c|c|c|c|c|c|c|}
\hline SW & ${ }^{+} \mathrm{d}_{\text {Mean }}$ & $-\mathrm{d}_{\text {Mean }}$ & $\mathrm{d}_{\text {Mean }}$ & ${ }^{+} \mathrm{d}_{\text {Max }}$ & $-\mathrm{d}_{\text {Max }}$ & $\sigma_{\mathrm{d}}$ \\
\hline Faro Scene & 0.007 & $\begin{array}{c}- \\
0.007\end{array}$ & 0.001 & 0.107 & $\begin{array}{c}- \\
0.081\end{array}$ & 0.011 \\
\hline $\begin{array}{l}\text { Leica } \\
\text { Cyclone }\end{array}$ & 0.006 & $\begin{array}{c}- \\
0.007\end{array}$ & 0.001 & 0.092 & $\begin{array}{c}- \\
0.075\end{array}$ & 0.011 \\
\hline $\begin{array}{l}\text { 3DVEM } \\
\text { Register }\end{array}$ & 0.006 & $\begin{array}{c}- \\
0.007\end{array}$ & 0.001 & 0.089 & $\begin{array}{c}- \\
0.079 \\
\end{array}$ & 0.010 \\
\hline
\end{tabular}

Table 1. Distance deviations between point clouds and meshes (in $\mathrm{m}$ )

Table 2 reports on the differences achieved among meshes.

\begin{tabular}{|c|c|c|c|c|c|c|}
\hline SW & ${ }^{+} \mathrm{d}_{\text {Mean }}$ & $-\mathrm{d}_{\text {Mean }}$ & $\mathrm{d}_{\text {Mean }}$ & ${ }^{+} \mathrm{d}_{\text {Max }}$ & $-\mathrm{d}_{\text {Max }}$ & $\sigma_{\mathrm{d}}$ \\
\hline $\begin{array}{c}\text { Scene- } \\
\text { Cyclone }\end{array}$ & 0.005 & 0.004 & 0.000 & 0.085 & -0.100 & 0.007 \\
\hline $\begin{array}{l}\text { 3DVEM- } \\
\text { Scene }\end{array}$ & 0.004 & $\begin{array}{c}- \\
0.005\end{array}$ & 0.000 & 0.072 & -0.086 & 0.007 \\
\hline $\begin{array}{l}\text { 3DVEM- } \\
\text { Cyclone }\end{array}$ & 0.001 & $\begin{array}{c}- \\
0.001\end{array}$ & 0.000 & 0.048 & -0.053 & 0.002 \\
\hline
\end{tabular}

Table 2. Comparison between the different results of the deviations mesh-mesh (in $\mathrm{m}$ )

As summary of the indirect registration step, obtained after using only spherical targets, we can make the following remarks: (1) the results show a substantial agreement between the three registration solutions. (2) 3DVEM $\AA$-Register software gives the error estimates for each station, therefore, it is very easy for the users to control the quality of the registration either in position and in orientation. The authors recommend the developers of the other two registration softwares to provide those estimates too.

\subsection{D model and detection of structural problems}

The survey executed by laser scanner highlights some aspects, not yet solved, regarding the form and the building history of the church: first of all, the shape of the dome. The masonry dome, built by using bricks, was often described erroneously as a hemisphere, similar to the Pantheon. Actually, the dome presents a radial symmetry, but the vertical section is obtained through two circular arches, with a radius of $28.50 \mathrm{~m}$. The building of the dome should have been very troublesome, due to its large dimensions. In correspondence to several dome slices, some cracks can be observed. Furthermore, the floor presents a slope: it is not clear if the slope is the same as in the original project, or if other problems occurred during construction.

4.2.1 Comparison between as-built (actual) and as-planned (ideal) shape of the dome - Thermal surveying - Cracks on the dome

The results of the laser scanner survey allowed us to obtain the deviations of the dome surface with respect to a likely designed (as-planned) surface. As reported above, the surface of the dome is quite different compared to a semi-sphere, so the diffused hypothesis about a "copy" of the Pantheon scheme is wrong.
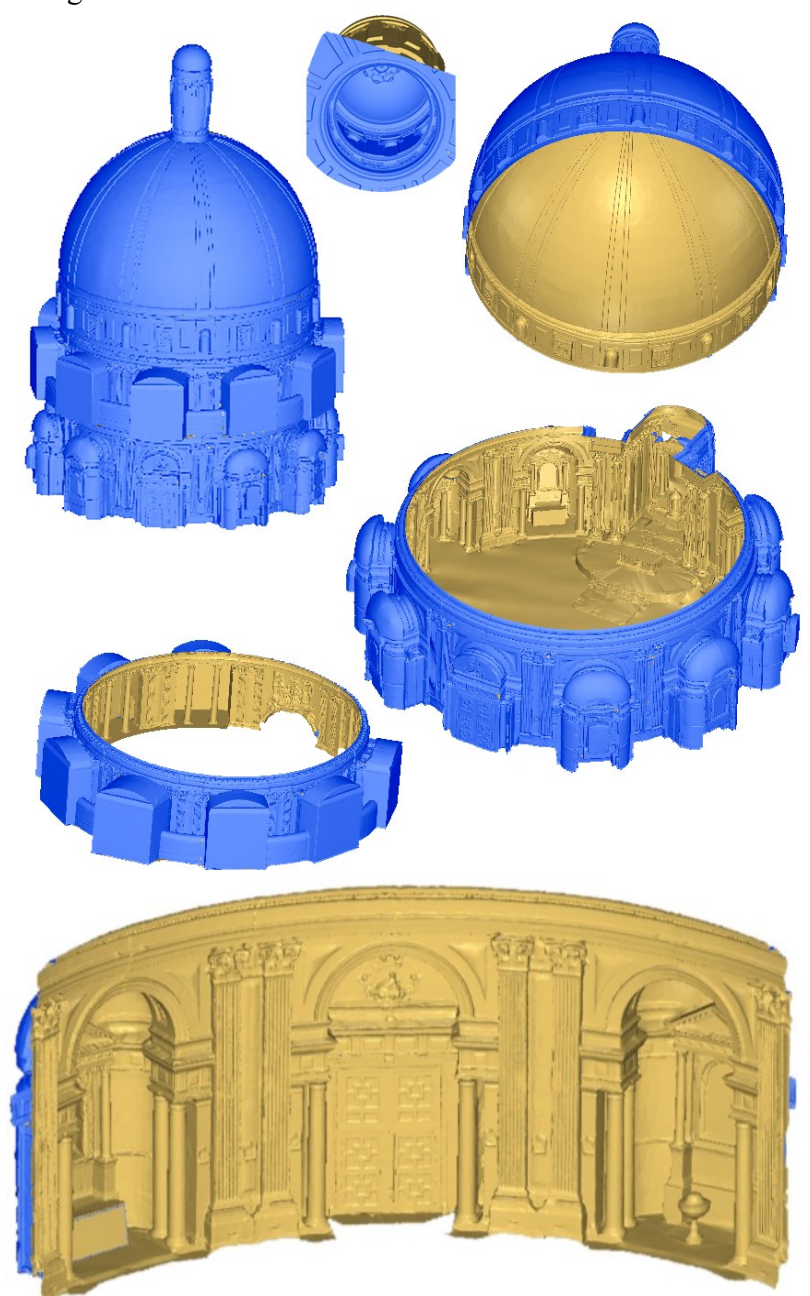

Figure 7. The 3D mesh of the Escuelas Pías Church 


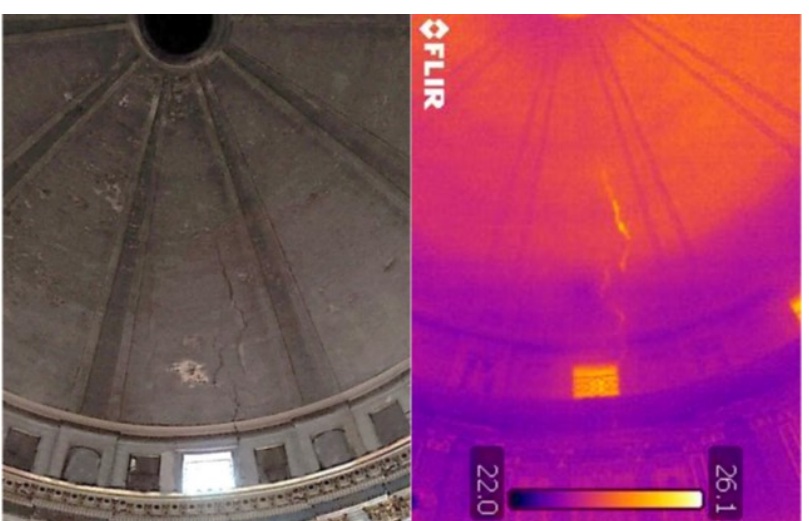

Figure 8 . The crack on a dome slice and the corresponding thermal image

The best fitting dome shape is obtained by considering a Bohemian vault. This hypothesis is confirmed by the 3D deviations between the actual and the ideal shape. It is highly interesting to highlight that the deviation between the real surface (best fitting ideal surface) and an ideal Bohemian vault (slice of the dome) is at a maximum near the cracks, where these are present.

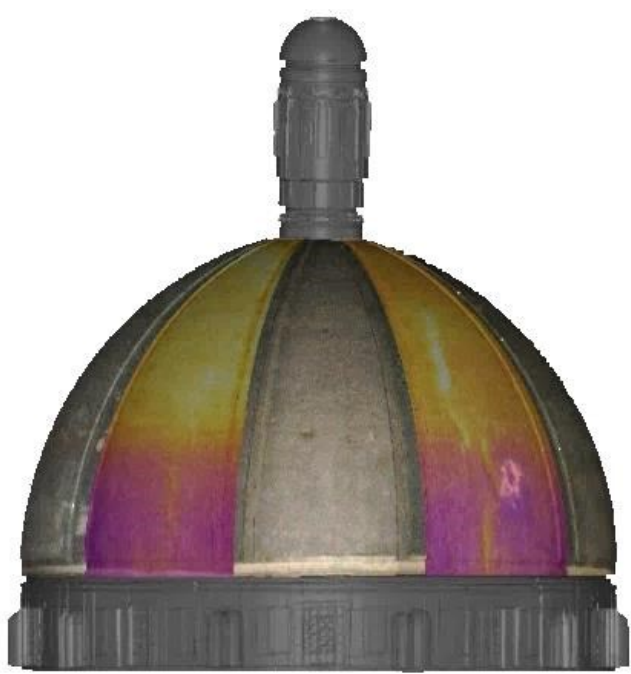

Figure 9. A view of the 3D model textured with the thermal image
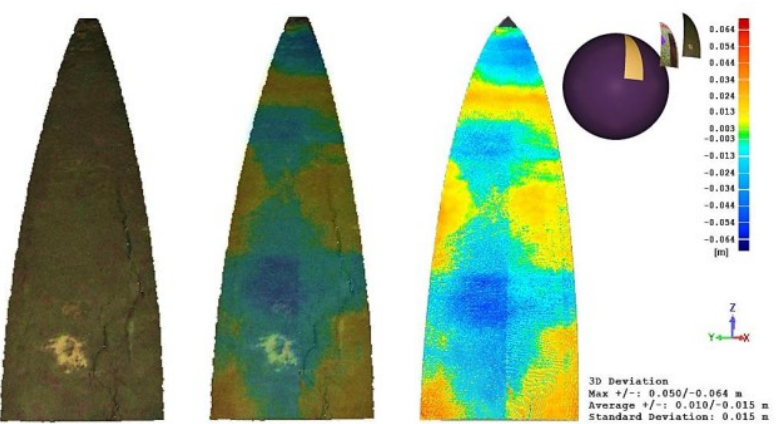

Figure 10. The deviations between the ideal and actual surface

In Figure 7, we can observe some details of the 3D mesh of the church at different levels. The cracks on a dome slice and the corresponding thermal image are shown in Figure 8. Figure 9 represents the $3 \mathrm{D}$ model textured with the thermal image. The deviations between ideal and actual surface are shown in Figure
10. It is worth observing that the maximum $3 \mathrm{D}$ deviations are about $5 \mathrm{~cm}$ (positive) and $6 \mathrm{~cm}$ (negative); the average deviations are about $1 \mathrm{~cm}$, while the standard deviation is 1.5 $\mathrm{cm}$. These values are compatible with the techniques used for the construction.

\subsubsection{The deviations of the symmetry axis}

Another question still open is related to the floor and the axis of drum, dome and lantern. The low slope, present in the floor, is not directed towards the main altar, but it has an orthogonal direction, so it is unlikely that it was foreseen in the original project. The axis of the church should give some information useful for hypothesizing the causes of the floor slope.

To find the axis of the church, horizontal sections were obtained on the 3D model every meter; the centroids of the sections were then found. The most likely axis should be the line that interpolates all centroids (Figure 11).

The axis found with the above-described procedure shows a deviation of about 0.44 degrees with respect to the vertical (from the floor to the top of the dome). The centroids move in the direction of the transept to the left for an observer looking at the principal altar. The floor of the church has a slope of about 0.137 degrees in the same direction. Since the biaxial compensator of both laser scanners used for the survey has a precision of 0.015 degrees, the slope of the floor can be stated that is real. Given that the deviation of the axis is to some degree greater than the slope of the floor, we could make the following hypotheses: (a) the whole church suffered a subsidence after its realization, (b) due to small errors during the building construction, the central axis was not vertical also at the end of its realization.
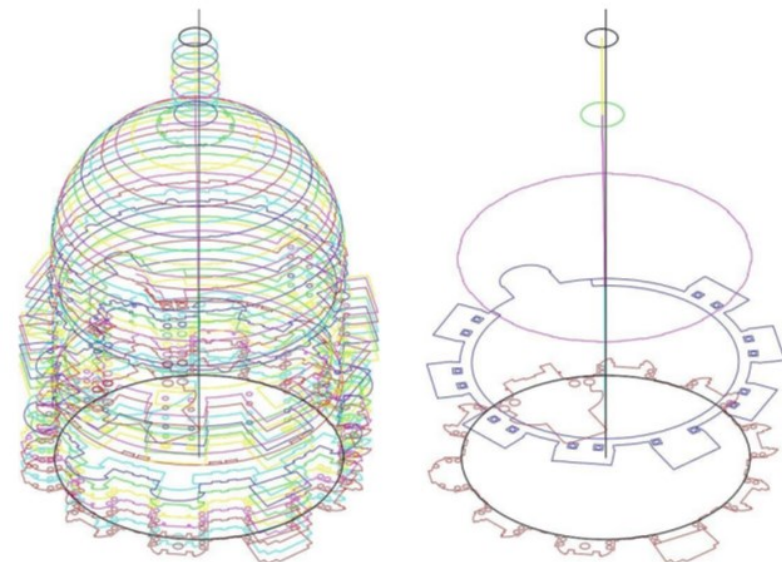

Figure 11. Axonometric view: the thin black line is vertical in the bottom centre

\section{CONCLUSIONS}

This paper describes the 3D documentation and survey of the Escuelas Pías Church in Valencia carried out by the authors to analyse the shape of the dome and the origin of the alterations that should be corrected to avoid unexpected problems.

The registration results achieved with the different software packages yield equivalent residuals when comparing point clouds and 3D models coming from the same software. The comparison between the meshes extracted from different point clouds confirms that the results have the same order of magnitude. 
The creation of the $3 \mathrm{D}$ model and the results of some investigations have allowed the formulation of not only hypothesis about the design of the dome but also the origin of the cracking alterations.

The data collected and the results of the processing offer useful information to architects, building technicians and structural engineers for reconstructing the building history and better understanding the origin of the structural problems of the church.

In the near future, a comprehensive report of the existing alterations between the as-built and as-planned Escuelas Pías Church using geomatics techniques will be drawn.

\section{REFERENCES}

Artese, S., Achilli, V., \& Zinno, R., 2018. Monitoring of Bridges by a Laser Pointer: Dynamic Measurement of Support Rotations and Elastic Line Displacements: Methodology and First Test. Sensors, 18(2), 338.

Artese, G., Perrelli, M., Artese, S., Meduri, S., \& Brogno, N., 2015. POIS, a low cost tilt and position sensor: design and first tests. Sensors, 15(5), pp. 10806-10824.

Artese, S., Altomare, C., Lerma, J. L., Zinno R., 2014. Terrestrial laser scanning registration analysis and its effects on a masterpiece dome. In: Proceedings of EUROMED 2014 International Conference on Cultural Heritage, 3-8 November 2014, Lymassol, Cyprus, ISBN: $9781907132476 \cdot 556$ pp 89-99.

Artese, S., 2014. The city model as a tool for participatory urban planning-a case study: the Bilotti open air museum of Cosenza. In: ISPRS Annals of Photogrammetry, Remote Sensing \& Spatial Information Sciences, 2(5), pp. 25-32.

Artese, G., De Napoli, L., \& Artese, S., 2013. TOF laser scanner for the surveying of statues: a test on a real case. In: The International Archives of the Photogrammetry, Remote Sensing and Spatial Information Sciences, 5, W2.

Besl, P. J., \& McKay, N. D., 1992, April. Method for registration of 3-D shapes. Sensor Fusion IV: Control Paradigms and Data Structures. International Society for Optics and Photonics, Vol. 1611, pp. 586-607.

El-Hakim, S. F., Beraldin, J. A., Picard, M., \& Godin, G., 2004. Detailed $3 \mathrm{D}$ reconstruction of large-scale heritage sites with integrated techniques. IEEE Computer Graphics and Applications, 24(3), pp. 21-29.

Fabado, S., Seguí, A. E., Cabrelles, M., Navarro, S., García-DeSan-Miguel, D., \& Lerma, J. L., 2013, July. 3DVEM Software modules for efficient management of point clouds and photorealistic 3D models. In ISPRS-International Archives of the Photogrammetry, Remote Sensing and Spatial Information Sciences, XXIV International CIPA Symposium, pp. 255-260.

Gressin, A., Mallet, C., Demantké, J., \& David, N., 2013. Towards 3D lidar point cloud registration improvement using optimal neighborhood knowledge. ISPRS journal of photogrammetry and remote sensing, 79, pp. 240-251.
Hammoudi, K., \& Dornaika, F., 2011. A featureless approach to 3D polyhedral building modeling from aerial images. Sensors, 11(1), 228-259.

Lerma, J. L., 2005. Automatic plotting of architectural facades with multispectral images. Journal of surveying engineering, 131(3), pp. 73-77.

Lerma García, J. L., Santana Quintero, M., Heine, E., \& Van Genechten, B. (Eds.), 2008. Theory and practice on terrestrial laser scanning. Training material bases on practical applications. Valencia: Editorial Universitat Politècnica de València.

Portalés, C., Lerma, J. L., \& Pérez, C., 2009. Photogrammetry and augmented reality for cultural heritage applications. The Photogrammetric Record, 24(128), pp. 316-331.

Remondino, F., Gruen, A., von Schwerin, J., Eisenbeiss, H., Rizzi, A., Sauerbier, M., \& Richards-Rissetto, H., 2009. Multisensor 3D documentation of the Maya site of Copan. In: Proceedings of 22nd CIPA Symposium, Kyoto, Japan.

Verdú, R. S., 1996. Cúpulas en la arquitectura valenciana de los siglos XVI a XVIII. In Actas del Primer Congreso Nacional de Historia de la Construcción, Vol. 19, p. 21.

Zhang, Z., 1994. Iterative point matching for registration of free-form curves and surfaces. International journal of computer vision, 13(2), pp. 119-152.

Zinno, R., Artese, S., Clausi, G., Magarò, F., Meduri, S., Miceli, A., \& Venneri, A., 2019. Structural Health Monitoring (SHM). The Internet of Things for Smart Urban Ecosystems. Springer, Cham, pp. 225-249 